\title{
Risk management and alarming based on a new atmospheric correction algorithm for ground-based radars
}

\author{
A Cabrejo GroundProbe Pty Ltd, Colombia \\ P Bellett GroundProbe Pty Ltd, Australia \\ G Stickley GroundProbe Pty Ltd, Australia \\ R Silva Compañía Minera Doña Inés de Collahuasi, Chile \\ Y Gunaris Compañía Minera Doña Inés de Collahuasi, Chile \\ J Pérez Compañía Minera Doña Inés de Collahuasi, Chile
}

\begin{abstract}
For the last five years, GroundProbe has been developing a new atmospheric correction technique, which has been tested for about three years at Collahuasi mine and other mines around the world. The challenging operational and atmospheric conditions at Collahuasi have allowed GroundProbe to further calibrate the algorithms to account for some of the most difficult conditions faced by the radar onsite. Collahuasi is a large open pit in northern Chile, with a combination of severe atmospheric conditions along the year which makes it a perfect scenario for testing and calibration of the new algorithm called precision atmospherics.
\end{abstract}

The algorithm was also tested in other large mine sites with challenging atmospheric conditions. A statistical analysis of the results is presented here, intending to quantify the improvement brought by the new method in regards to the reduction of noise and ability to better detect ongoing deformations.

This new algorithm has been designed to overcome some of the limitations of current atmospheric correction methods that exist in the current technology while guaranteeing the same reliability of existent techniques in the market. During this testing period, we managed to compare the data from traditional GroundProbe algorithms against data from precision atmospherics on live operational mode, and the improvements in the capability of detection of rapid instabilities, and the ability to easily differentiate noise from real displacements have been highly valued.

As a consequence of the improvements in the quality of the data, it is now possible to use tighter alarms during real-time monitoring, as an extra aid to the 24/7 monitoring team onsite. This allows better risk management and reduction of uncertainty.

Keywords: atmospheric correction, precision atmospherics algorithm

\section{Introduction}

Open pits have been monitored for over a decade using ground-based interferometric radar technology. The application of the technology has been extended from small open pits to the largest pits around the world in a wide variety of atmospheric conditions and complex distribution of the atmospheric properties across the open pit. This natural extension of the application has introduced difficulties to the atmospheric corrected required to deliver very high-quality displacement data, commonly known as atmospheric noise or atmospheric contamination. Different radar suppliers and researchers have developed different techniques to deal with the atmospheric problem, each one with its advantages and disadvantages. In this paper, a new technique is presented after a few years of testing on real scenarios of high complexity. This new algorithm will be described as precision atmospherics (PA) algorithm. 


\section{Technical background}

\subsection{Applied interferometry technique}

Radar interferometry is a remote sensing technique applied in space-borne and ground-based technologies for open pit mines and other civil applications. It aims to estimate movement on targets with submillimetre accuracy at rates that are suitable to the application at hand, which, in our particular case, is the movement in open pit walls and natural slopes. The need for high accuracy originates from the natural movement and displacement rates of rocks and soils before collapses are triggered. In order to have an opportune warning on the commencement of a slope failure, it is necessary to detect small displacements with submillimetre accuracy, allowing the opportune evacuation of personnel and equipment.

The interferometry technique estimates the difference in the phase angle of two consecutive returning signals from a slope (phasors). Figure 1 represents the phase shift between two consecutive scans after some slope movement has occurred. Basically, a phasor is a rotating vector that has a phase and an amplitude at any given time, and it is the difference in the phase angle of two consecutive phasors that allows the interferometry technique to be applied.

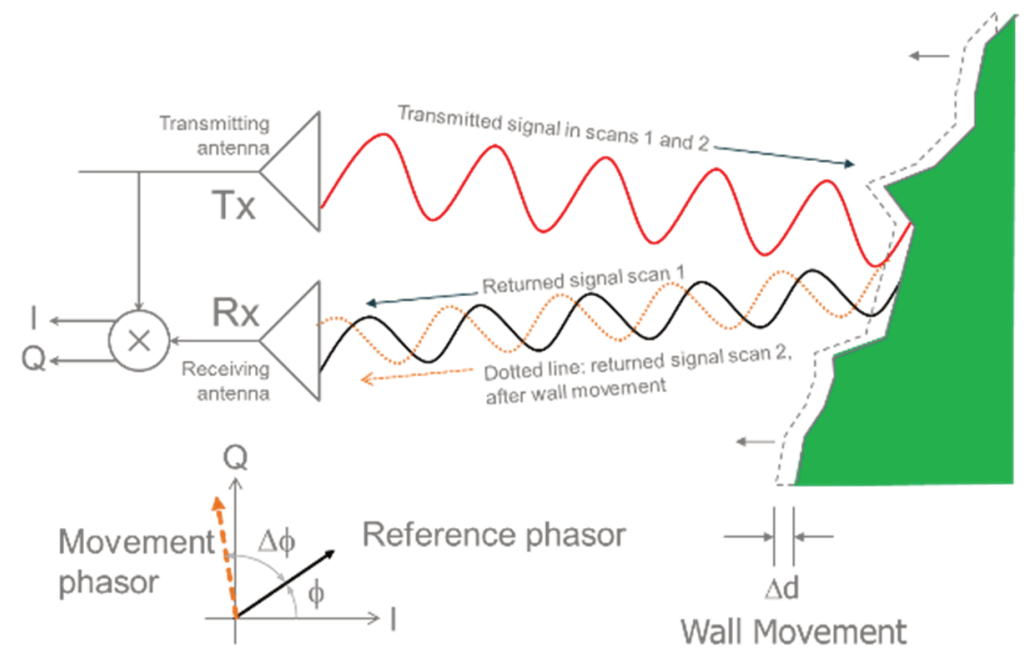

Figure 1 Simplified representation of the interferometry technique

If no movement has occurred on the target between scan 1 and scan 2, the phase angle of the incoming signal stays constant. If movement has occurred between scan 1 and scan 2 , there will be a difference in phase angle which can be converted into displacement. The equations and maths of the technique are available in the literature (Pieraccini 2019; Reeves 2001) and will not be further described here. Figure 2 represents one phase shift from 90 to $225^{\circ}$ and its equivalent amount of movement that could be derived from this interferometric reading. Note that the vertical axis is showing an interval from $+8 \mathrm{~mm}$ and $-8 \mathrm{~mm}$.

Phase rotation Deformation change

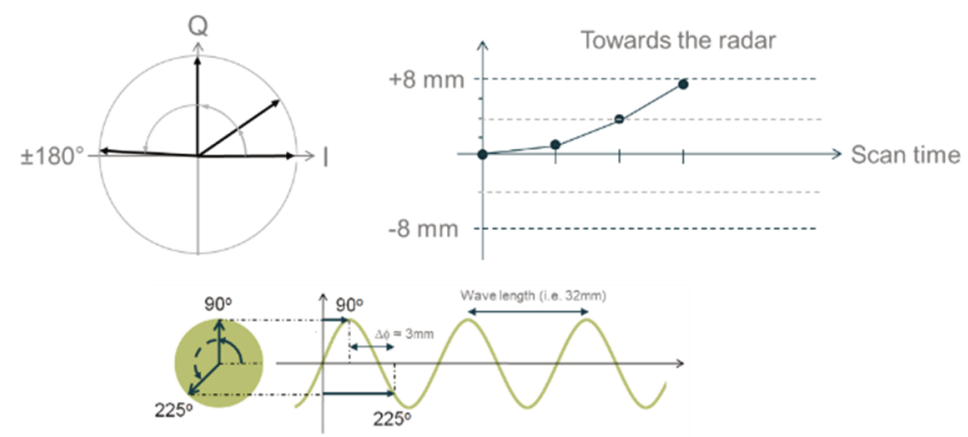

Figure 2 From interferometry to displacement 
This displacement range (ruler) is determined by the wavelength of the signal used (tied to its frequency). In real aperture radars (RAR) in the mining industry, this value typically ranges from $-8 \mathrm{~mm}$ to $+8 \mathrm{~mm}$, while in synthetic aperture radars (SAR), it ranges approximately from $-4 \mathrm{~mm}$ to $+4 \mathrm{~mm}$. RAR work with frequencies of the order of 9. The difference comes from the $9.5 \mathrm{MHz}$ of frequency used in the RAR and the $17 \mathrm{MHz}$ used in the SAR systems.

Figure 3 represents a simplified version of what phase and displacement ambiguity are. Since the interferometry technique is based on the measurement of phase angle change and phase angles are in cycles from 0 to $2 \pi$, the same phase angle could exist as many times as cycles are in the whole travel path from the radar to the target and back. The radar does not count cycles nor determine the cycle number that is returning to it. It only measures the phase angle of the returning signal. Because of this, the interferometry technique, as described earlier, is only appropriate for slow-moving targets, meaning deformations typical for mine sites as a natural rock mass response, and the maximum detectable rate is dependent on the wavelength of the signal, typically within the order of $8 \mathrm{~mm}$ for RAR and $4 \mathrm{~mm}$ for SAR on the ground. By slow movements, we are making reference to the velocity of a deforming rock mass prior to collapse which remains coherent to the radar, as opposed to that velocity achieved by a rock mass in free fall which is incoherent for a radar and impossible to track its displacement with the interferometry technique described above.

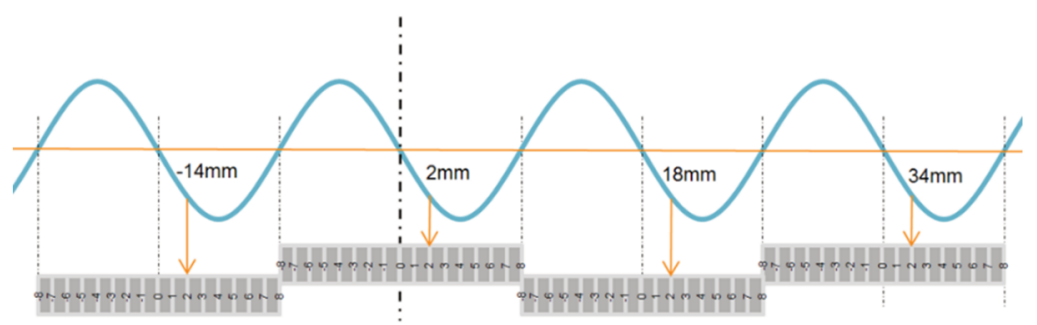

Figure 3 Phase and displacement ambiguity

With InSAR applications from space, other wavelengths are used but are not considered here. In practical terms, phase and displacement ambiguity mean that any target moving faster than the maximum detectable rate (i.e. $8 \mathrm{~mm}$ per scan in a RAR and $4 \mathrm{~mm}$ per scan in a SAR) will not be properly measured by the radar.

Any displacement beyond this maximum detectable rate between consecutive scans will be represented erroneously (fringes will be observed) unless a phase unwrapping correcting technique is applied, however, in real-time, ground-based radars, it might be unnecessary since the ground is moving already too fast that other risk control measures should have taken place already.

In Figure 4, an example of a real case is presented. Note the sharp change from red to purple colours (from towards movement to away movement) between consecutive scans (fringes). Nature does not behave like that. Such fringes are generated as a limitation of the radar to measure movements faster than $8 \mathrm{~mm} / \mathrm{scan}$, in that particular case.

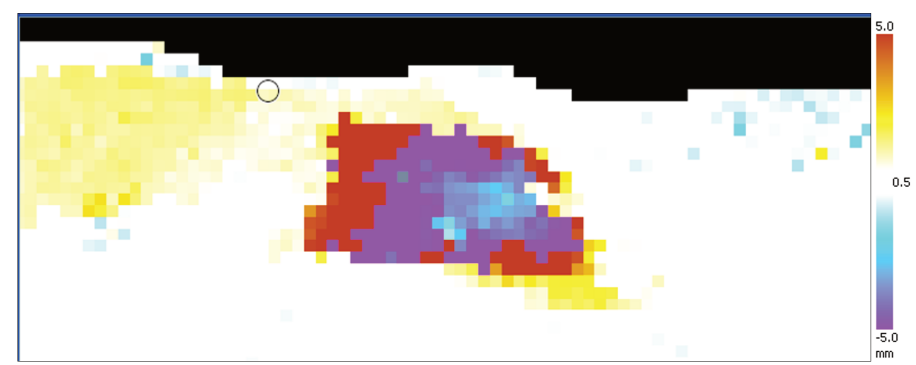

Figure 4 Example of a real case of displacement ambiguity on a rapid moving ground

Figures 1 to 4 and their associated concepts are, in the opinion of the authors, some of the most important concepts for geotechnical interpretation of data from interferometric radars. Based on our experience 
providing training to geotechnical engineers around the world, these concepts are key to correlate radar data with geotechnical events.

\subsection{Data acquisition process}

Figure 5 represents a simplified view of the whole radar process from the radar signal generation steps, all the way through data acquisition and atmospheric corrections, to the final display of displacement images. Notice the steps where the two types of radar technologies (3D-RAR and 2D-SAR) diverge from each other, which is basically at the step in which the radar signal is spread to the wall. While 3D-RAR systems focus all their energy on a pixel-by-pixel basis, the SAR systems shoot all the energy to the entire wall from different positions along the rail (linear positioner) (Bellett et al. 2018).

Also, while the 3D-RAR radars independently measure the signal scattered-back from each pixel, the SAR systems need to perform mathematical processing to generate synthetic beams and range pixels. Once the process of imaging the wall is completed, the interferometry and atmospheric correction steps take place. The process of atmospheric correction has two steps: first, the atmosphere needs to be characterised and second, the amount of atmospheric correction is estimated and applied. At the end, both radar technologies deliver a displacement radar image and other supporting maps and plots to help understand the data collected by the radar. The main focus of this paper is on the last steps-atmospheric characterisation and compensation-before the generation of the images. The generation of the right radar signals, beam forming, beam focussing, storing, mathematical processing and interferometry are, in general, processes well under control, leaving only the atmospheric management as the critical step to address.

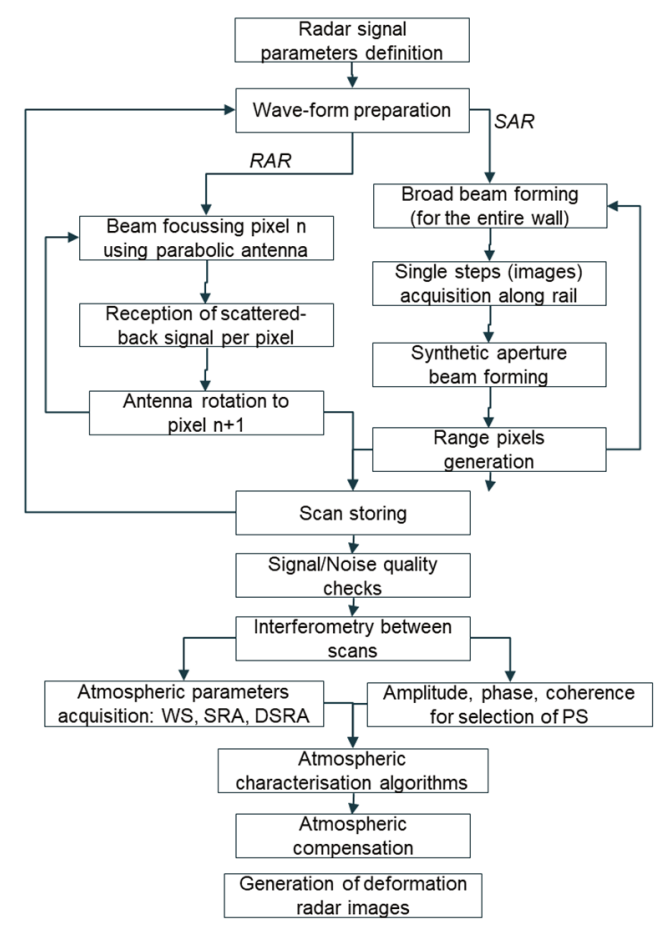

Figure 5 Simplified process of radar data acquisition for geotechnical engineers and non-radar experts

\subsection{Atmospheric behaviour, characterisation and correction techniques}

\subsubsection{Atmospheric variability}

Atmosphere is not homogeneous, and the larger the air volume involved in a radar measurement, the larger the influence of such variability. The variability of the atmosphere is caused by changes in temperature, pressure, and humidity which lead to changes in the overall density or amount of water vapour in the air, which changes the speed at which the signal travels through the air, and consequently, the phase angle that is measured by the radar and the displacement associated to it. Figure 6 shows the atmosphere change 
process that leads to atmospheric-induced displacement. In the same way, wall displacement can introduce a phase shift in the returning signal which the atmospheric changes can do as well Figure 7.

Radars were developed in experimental conditions which were then brought into the real world in small open pits of no more than a couple of hundred metres. Nowadays, radar technology is reaching targets up to $4,000 \mathrm{~m}$ in the largest open pits in the world. The atmospheric variability has gone from negligible in the $100 \mathrm{~m}$ distances to a condition that could be described as the existence of different micro-climates inside the same open pit and the surroundings towards the waste piles.

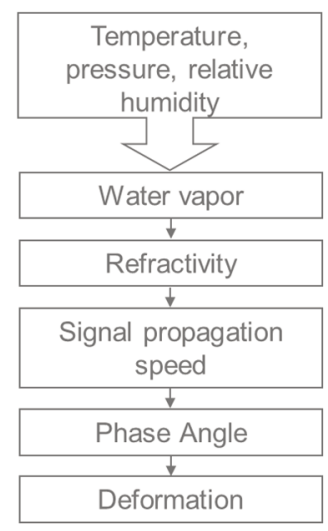

Figure 6 Influence of atmospheric parameters in displacement measurements using interferometry

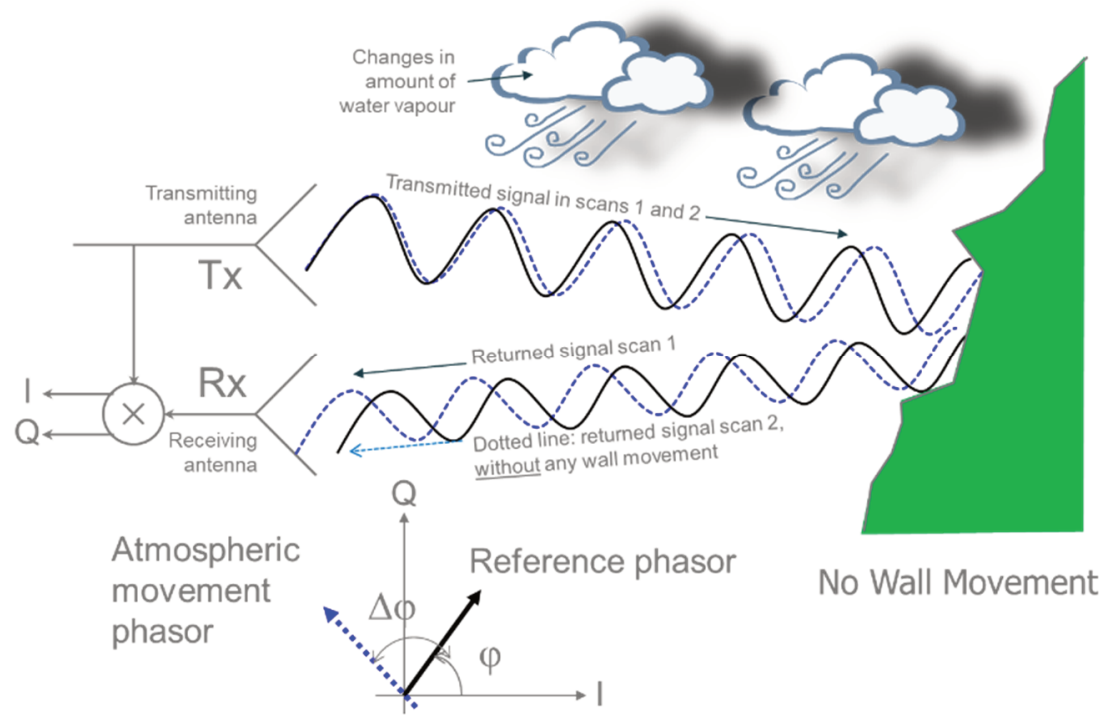

Figure 7 Atmospheric-induced apparent movement

Over the years, the industry has extended the range at which the radars are used, also as a natural need based on the deeper and wider open pits now compared to 20 years ago. This has introduced other needs like better resolution (smaller pixel size), faster scanning, and better atmospheric correction. Also, the geotechnical needs have pushed the application of the radars to the detection of rapid brittle failures which display small displacements over a short period of time that could easily be hidden at very long ranges or atmospheric clutter. These geotechnical needs have pushed radar researchers to develop faster radars that can scan wider angles and longer ranges, without losing the accuracy the interferometry technique originally brought into the geotechnical world.

\subsubsection{Atmospheric correction techniques}

There have been several atmospheric correction methods developed and Table 1 briefly describes some of the key characteristics. 
Table 1 Available atmospheric correction techniques, advantages and disadvantages

\begin{tabular}{|c|c|}
\hline $\begin{array}{l}\text { Correction } \\
\text { technique }\end{array}$ & Description \\
\hline $\begin{array}{l}\text { Weather } \\
\text { station (WS) }\end{array}$ & $\begin{array}{l}\text { A weather station installed at the radar } \\
\text { samples the atmosphere for } \\
\text { temperature, pressure and relative } \\
\text { humidity. Based on these readings the } \\
\text { algorithm calculates the atmospheric } \\
\text { refractivity representative for each scan. } \\
\text { Then the refractivity change from one } \\
\text { scan to the next one is calculated, and } \\
\text { the corrections calculated based on this } \\
\text { change. }\end{array}$ \\
\hline $\begin{array}{l}\text { Stable } \\
\text { reference } \\
\text { areas (SRA) }\end{array}$ & $\begin{array}{l}\text { The user defines points or areas in the } \\
\text { scan scene that will be recognised by } \\
\text { the radar as if they were stable. Any } \\
\text { displacement measured on them will be } \\
\text { considered as induced by atmospheric } \\
\text { changes and will be corrected. The } \\
\text { representative amount of correction } \\
\text { based on the SRA is then extrapolated to } \\
\text { the rest of the scan area proportional to } \\
\text { the distance between the radar and } \\
\text { each pixel. The shorter the range, the } \\
\text { smaller the correction. The longer the } \\
\text { range, the larger the correction. In the } \\
\text { SRA methodology used by the authors, } \\
\text { there is no spatial characterisation of } \\
\text { the atmosphere in 3D across the whole } \\
\text { scan area. }\end{array}$ \\
\hline
\end{tabular}

\section{Advantages, disadvantages and application}

Advantages: simple method based purely on weather data. No use of any radar measurement to correct radar measurements.

Disadvantage: not applicable in large pits or where the atmosphere is not homogeneous.

Application: from our experience, when the range is short, for instance, less than $400 \mathrm{~m}$, the WS method could provide sufficiently good results. This is ideal for situations when there are no stable and coherent areas in the scene to use as reference areas to estimate atmospheric change. In strip mines, when scanning the low walls from the highwall this tool is very valuable.

Advantages: simple, controlled by the geotechnical engineers based on their geotechnical understanding of the scanned area. Easy to understand if one of the references is moving and improvements can be made.

Disadvantages: not automated, requires maintenance by geotechnical engineers. Requires users training to identify potential errors induced by movement on those SRAs.

Application: this technique has been used in real aperture radars since its development. It has been used in virtually every type of mine, weather and commodity in the mining industry.

Technique applied throughout the whole story of real aperture ground-based radars. The technique has sometimes proven insufficient in large pits or with very inhomogeneous atmosphere due to the lack of 3D characterisation. The errors in the estimation of the correct amount of atmospheric correction leave traces of noise that can sometimes make the data interpretation complex. This limitation is normally addressed by deploying the radar at a shorter range and in a fast scan mode in order to minimise the effect of the atmospheric.

Dynamic Same as SRA, but the algorithm stable reference automatically rejects pixels with low coherence.

areas

(DSRA)

Persistent The algorithm tracks the statistical scatters (PS) behaviour of the pixels in the scan scenario, looking for spatial and temporal correlation (or decorrelation) in order to classify the areas suitable for atmospheric correction. Typically, the PS technique uses correlations of amplitude, coherence and phase changes to determine the suitability of a persistent scatterer.

There are several methodologies to determine the best scatterers for atmospheric correction that can be researched in the literature (see Crosetto et al. 2016.)
Advantages: The issue of maintenance of the stable reference areas is reduced as drops in coherence is addressed automatically by the software.

Disadvantage: Same as SRA but at a lesser degree.

Application: Same as SRA, and even more extensively around the world.

Advantages: simplicity of use is one of the key advantages, as the algorithm works in an automatic manner which translates in less maintenance by the user. This technique, in combination with fast scanning from a ground-based SAR radar led to a significant improvement in the long-term and background monitoring in open pit mines around the world.

Disadvantage: the radar user is taken away from controlling which areas are suitable for atmospheric correction. It also takes some time to build up statistics of the atmosphere that could take time to self-calibrate. In real-world mine scenarios, the PS technique has sometimes led to under-estimation of slope displacement in mining environments of up to $89 \%$ compared to SRA either using RAR or SAR technologies. 


\section{Precision atmospherics algorithm}

The limitations of the techniques mentioned earlier have led to the need for developing a new algorithm to address the limitations described, without losing any of their advantages. For this, GroundProbe scientists have been investigating new techniques to address the issues observed in complex environments around the world using RAR and DSRAs for over four years. The result is a new algorithm called PA, which is designed to preserve the safety and reliability demonstrated by the SRA technique used in RAR and SAR systems while addressing spatial atmospherics issues. In addition to this, a key development focus was to not suppress displacement, especially from areas moving fast to failure, as observed in real cases with the PS technique.

Based on over two decades of experience and understanding of the geotechnical behaviour of ground movements, we have focussed the development of this new algorithm with a final geotechnical set of outcomes in mind:

1. Detection of long-term movements.

2. Detection of rapid movements.

3. Delivery of the same safety-critical data as with SRAs.

4. Avoid suppressing real wall movement.

5. Some involvement of geotechnical practitioner in the decision-making process.

6. Avoidance of automatic decisions made by a system that does not know the behaviour of the atmosphere or the rocks.

7. Simplicity.

8. Avoid any time-lag that could lead to undetected failures.

9. Avoid the use of super computers to run.

10.Safe introduction to the industry with easy comparison and complementary use with the SRA method.

11.Applicability in a variety of atmospheres with snow, rain, dust, heat, etc.

12.Keep records of blasting and mining activity in the pit for safety-critical applications.

The result of this new proprietary technology represents an improvement in the data obtained from ground-based radars. The following case studies show the results of the new technique compared to the previous one, and the improvements made to the data quality and cleanliness of plots and maps. The objective of not suppressing deformation compared to the SRA technique was also achieved and shown in the case studies below. The algorithm is currently limited to 2D-RAR systems (SSR-FX and SSR-OMNI).

\section{$4 \quad$ Case studies}

In this section we will present examples of the quality of the images obtained with this PA on a couple of challenging mine sites around the world. For confidentiality, names are not disclosed, neither are the full images of the pits to avoid identification. In all the examples, we present the PA algorithm compared against the enhanced deformation algorithm, which is the algorithm that processes the atmospheric correction based on dynamic stable reference areas (DSRA). The algorithm was tested in the 2D-RAR systems, SSR-FX and SSR-OMNI produced by GroundProbe.

\subsection{Case 1: site with layered atmosphere 'Chilean Camanchaca'}

This site is a mine in Chile where the 'Camanchaca' effect takes place. The Camanchaca is a phenomenon by which dense fog comes in a layer and covers, for instance, the upper half of the pit and stays there for hours. It is a rapid change that arrives and stays for a period of time longer than normally seen in open other pits in the world. 
Figure 8 shows two displacement plots, one with DSRA method and the other with PA. The difference in the noise level is largely noticeable. In Figure 9, the difference between the algorithms and an ideal linear trend is shown. It is assumed that the perfect linear trend represented the real behaviour of the wall. While the DSRA displacement delivers errors of up to $10 \mathrm{~mm}$, the PA shows errors within $2 \mathrm{~mm}$. The most significant differences occur in periods of 12 hours, towards midnight and midday when the atmosphere is more turbulent.

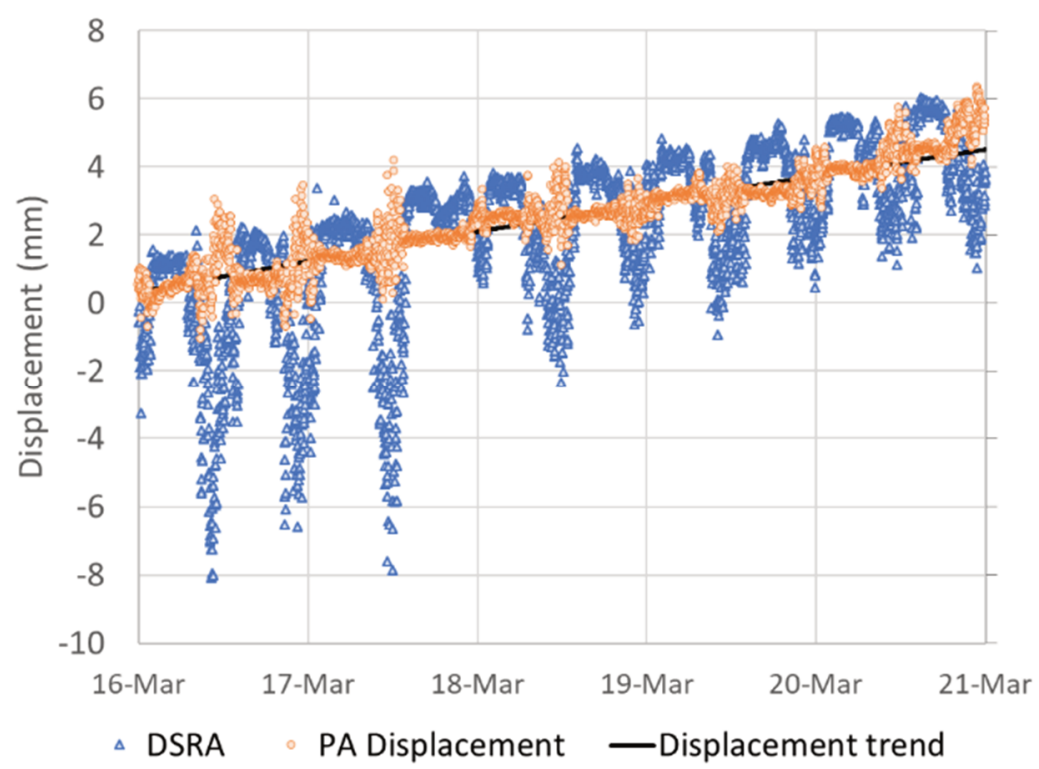

Figure 8 Structurally-controlled movement. Mine with Camanchaca. Pixel at $900 \mathrm{~m}$ range. Dynamic stable reference areas versus precision atmospherics

A statistical analysis of the data is shown in Figures 10 and 11. The histograms compare errors (or residual atmospheric clutter) using PA and DSRAs. Figure 10 uses total accumulated displacement and Figure 11 is for scan-by-scan displacement. From the histogram in Figure 10, it can be concluded that the noise distribution is better and smaller with PA with a central value of zero and a narrow spread compared to DSRA that spreads all the way from $-5 \mathrm{~mm}$ to $1.6 \mathrm{~mm}$. The median and the standard deviation were reduced by at least 1 order of magnitude with PA. Refer to results in Table 2.

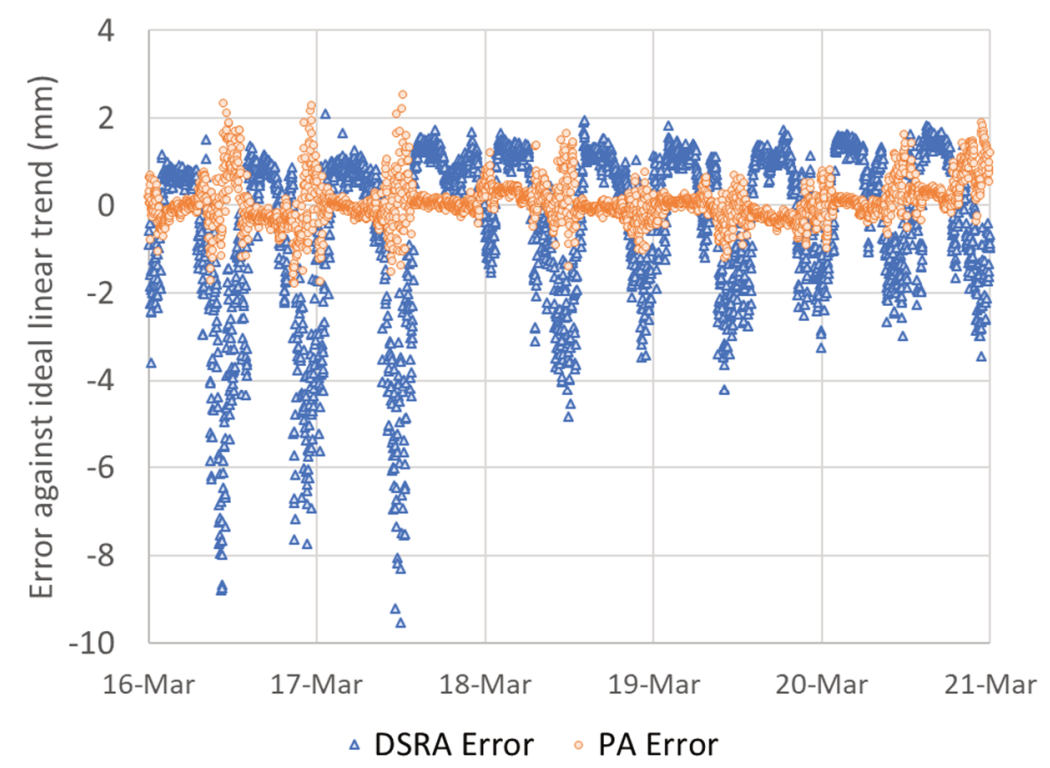

Figure 9 Structurally-controlled movement. Pixel at $900 \mathrm{~m}$ range. Errors of dynamic stable reference areas and precision atmospherics against an ideal linear trend 


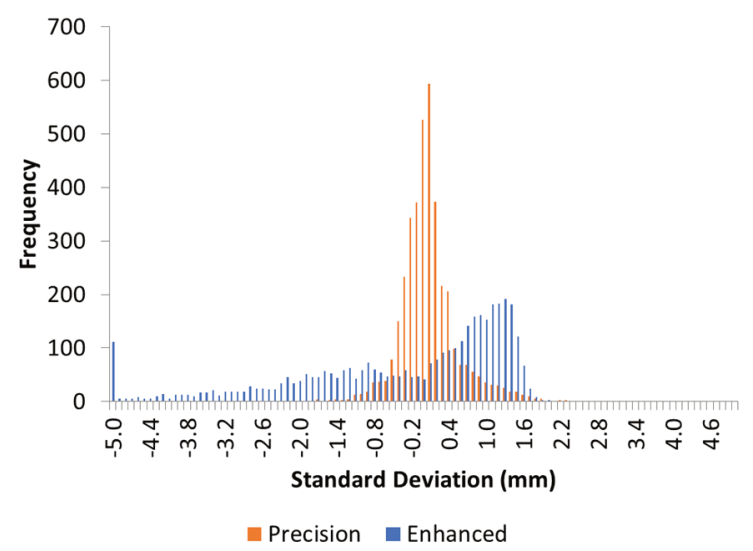

Figure 10 Structurally-controlled movement. Histogram of errors on total accumulated displacement using precision atmospherics and enhanced deformation

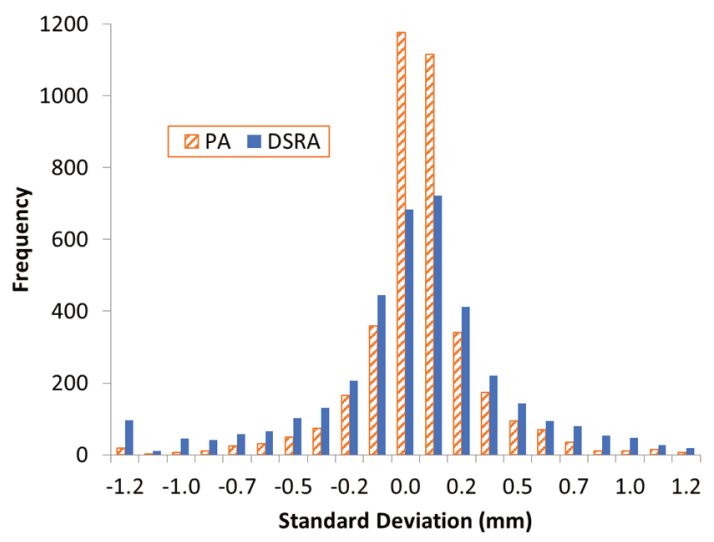

Figure 11 Structurally-controlled movement. Histograms of errors on delta displacement (scan-by-scan) using precision atmospherics and enhanced deformation

Figure 11 shows the same analysis on a scan-by-scan basis so that the accumulation of unwanted noise is disregarded from the analysis. In this analysis, the histograms are both centred instead of skewed, which is the expected case. What is important is the concentration of measurements more towards the centre of the histogram, with PA compared against DSRA.

Table 2 Case 1 statistics: precision atmospherics versus dynamic stable reference areas

\begin{tabular}{lll}
\hline Parameter & Precision atmospherics & Dynamic stable reference areas \\
\hline Average & $2.40 \mathrm{E}-08$ & $-4.16 \mathrm{E}-01$ \\
Median & $-1.87 \mathrm{E}-02$ & $2.92 \mathrm{E}-01$ \\
Standard deviation & $4.28 \mathrm{E}-01$ & $1.86 \mathrm{E}+00$ \\
Max & $2.52 \mathrm{E}+00$ & $2.10 \mathrm{E}+00$ \\
Min & $-1.80 \mathrm{E}+00$ & $-9.53 \mathrm{E}+00$ \\
Range & $4.32 \mathrm{E}+00$ & $1.16 \mathrm{E}+01$ \\
\hline
\end{tabular}




\subsection{Case 2: high altitude, extreme atmospherics and 'viento blanco'}

\subsubsection{Waste dumps at long range $(2,200 \mathrm{~m})$}

Collahuasi is a mine site in northern Chile, above 4300 m.a.s.l., that experiences very strong atmospheric conditions, in particular the 'viento blanco' effect which is wind with snowflakes in the air. It is a large mine, exceeding the $2.8 \mathrm{~km}$ range and $1 \mathrm{~km}$ depth, with dumps outside the pit and at longer ranges $(3,000 \mathrm{~m}$ or more), and with significant atmospheric contamination that the SSR-FX radars have helped address. Collahuasi and GroundProbe have collaborated for the last three years in the testing and improvement of the PA algorithm given the strong events that take place in there. Figure 12 shows a corrected displacement image obtained with PA at long range, showing very clear long-term data that was usually very difficult to clearly visualise in DSRA displacement maps. Figure 13 shows the displacement plots going away from the radar with the two algorithms, with PA performing much better.

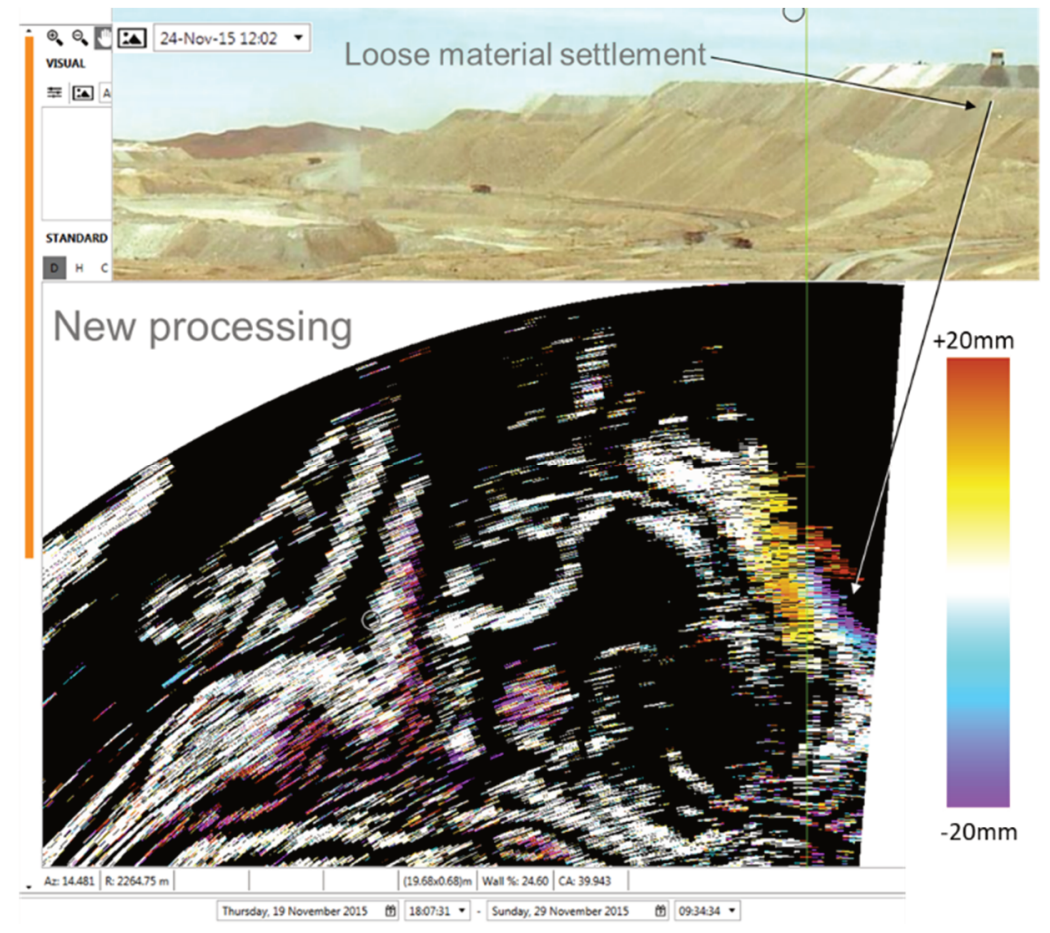

Figure 12 Displacement image of dumps settlement

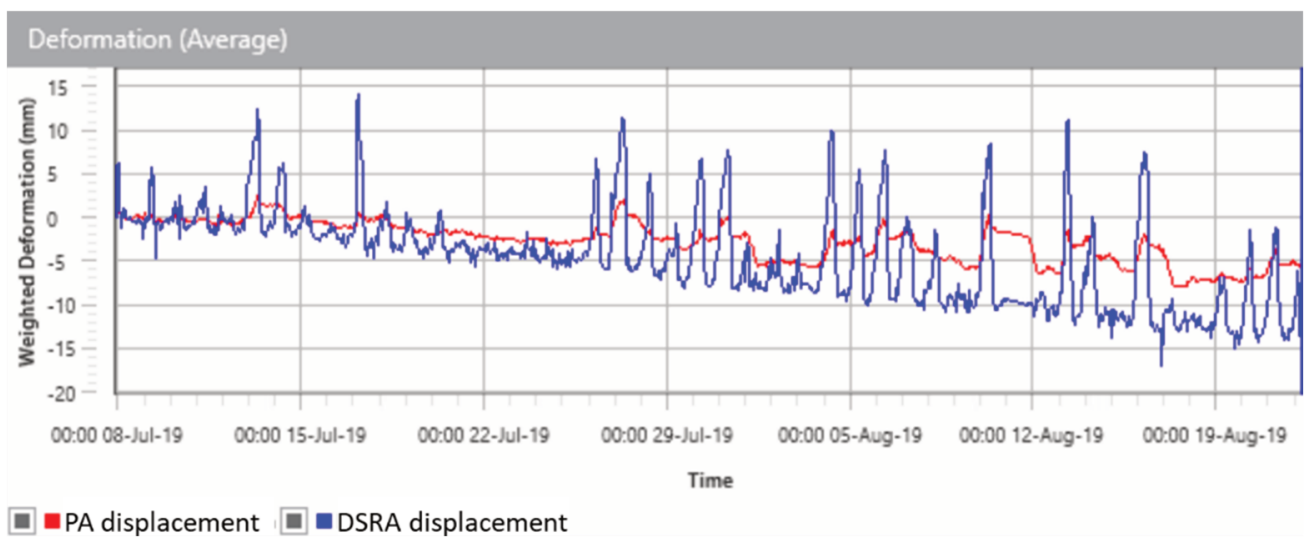

Figure 13 Precision atmospherics versus dynamic stable reference areas displacement versus time in a dump at long range 


\subsubsection{Slow movement at $1,600 \mathrm{~m}$}

Figure 14 shows the difference in the displacement readings on an area of the mine that is moving at a very slow rate. While the trend with DSRA corrected displacement (blue plot) is difficult to interpret, the PA plot (orange) clearly shows $2 \mathrm{~mm}$ of displacement accumulated during the monitoring period. Figure 15 shows the histograms of noise on total accumulated displacement, with the DSRA showing larger errors spread across the histogram compared to the PA displacement that delivers errors with submillimetre accuracy. The spatial extent of this slow-moving area was also clearly visible in the PA displacement images and difficult to see in SRA displacement images. Table 3 shows the improvement on scan-by-scan: average in two orders of magnitude and median in one order of magnitude, and the DSRA displacement was reduced to a third, falling within the submillimetre accuracy offered commercially with the radars $(0.1 \mathrm{~mm})$; the noise reduction can also be appreciated in Figure 16.

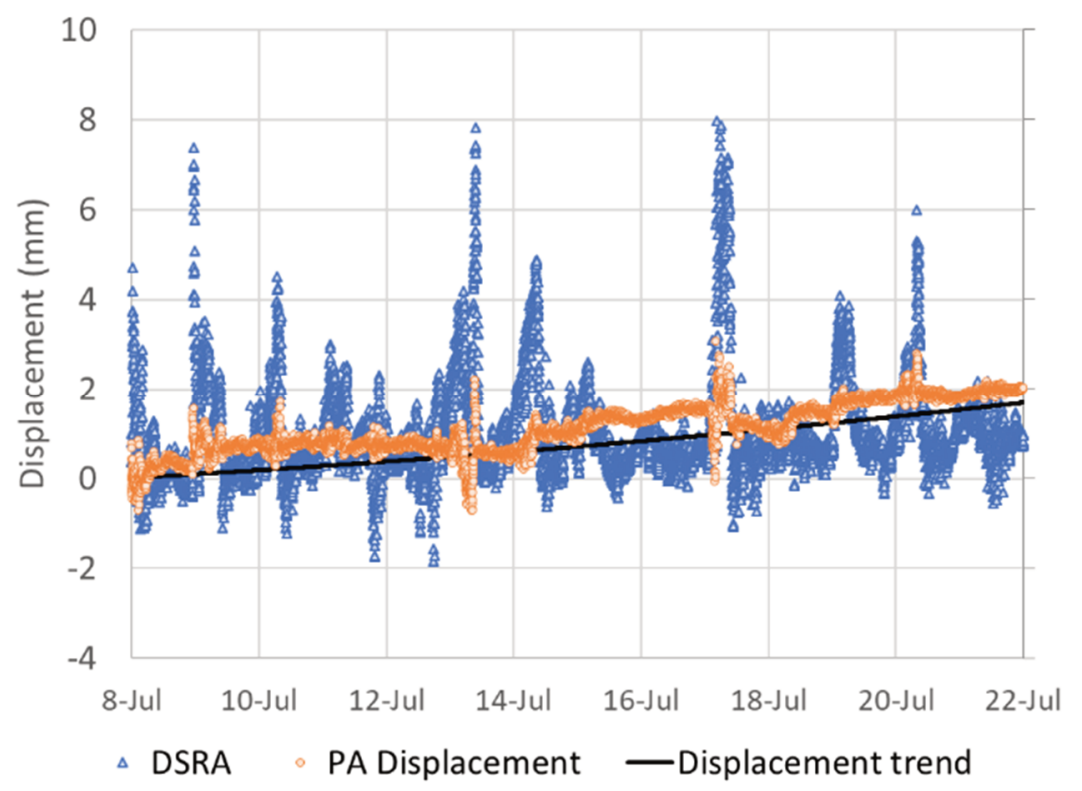

Figure 14 Slow movement: dynamic stable reference areas versus precision atmospherics on a slowmoving area

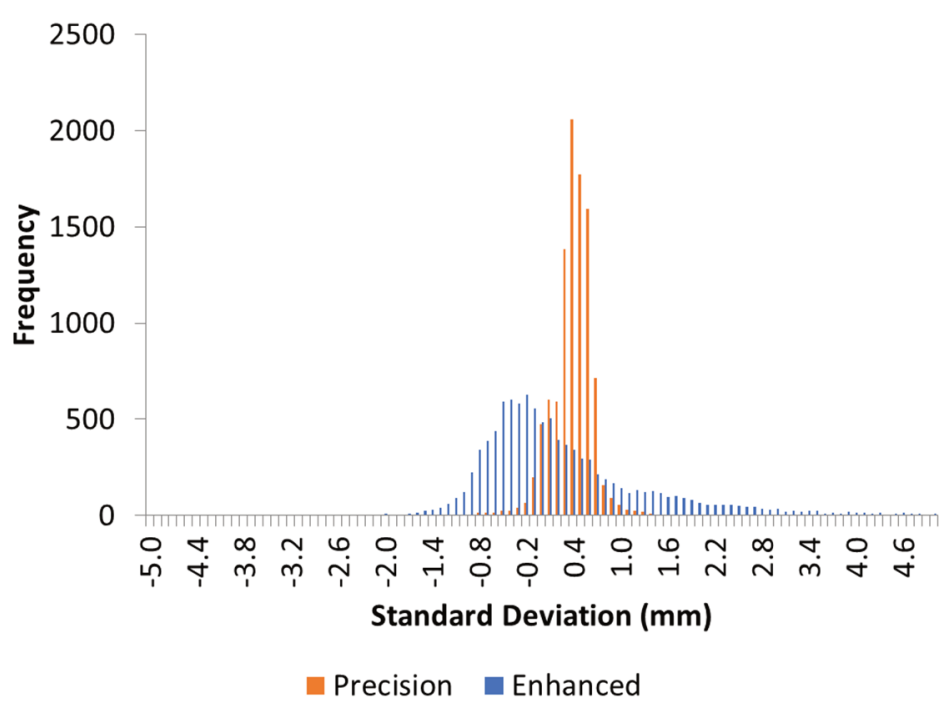

Figure 15 Slow movement: histogram of errors on total accumulated displacement using precision atmospherics and dynamic stable reference areas 


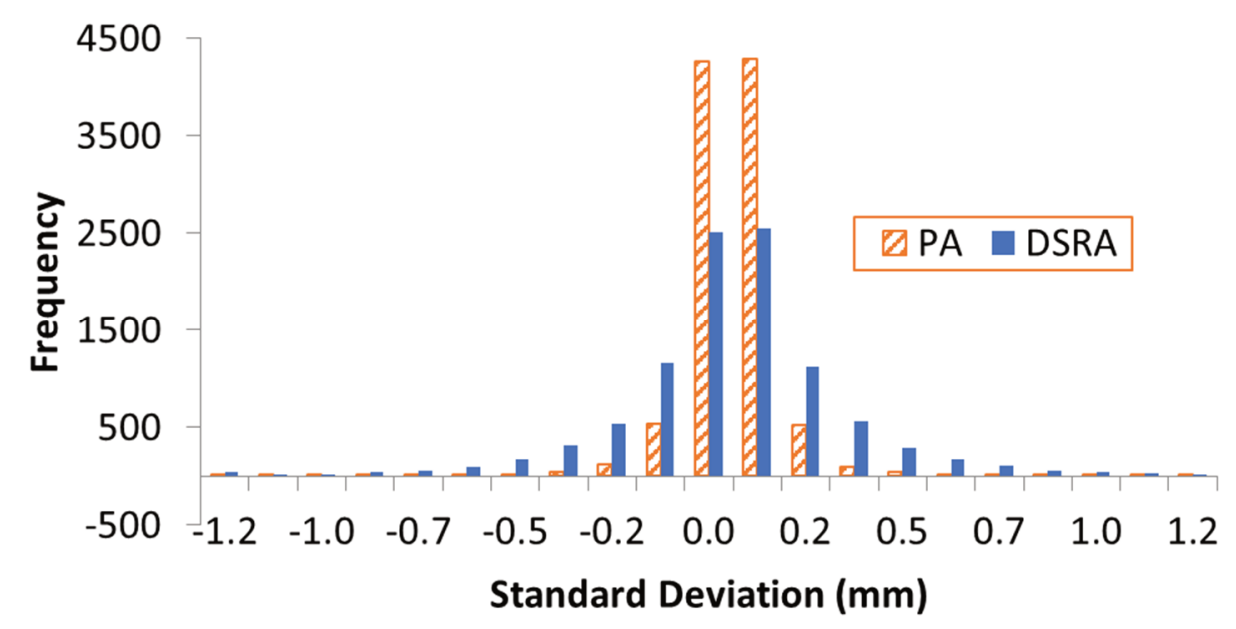

Figure 16 Slow movement: errors histograms on delta displacement (scan-by-scan) using precision atmospherics and dynamic stable reference areas

Table 3 Slow movement statistics: precision atmospherics versus dynamic stable reference areas displacement

\begin{tabular}{lll}
\hline Parameter & Precision atmospherics & Dynamic stable reference areas \\
\hline Average & $6.52 \mathrm{E}-05$ & $9.79 \mathrm{E}-07$ \\
Median & $2.40 \mathrm{E}-05$ & $2.59 \mathrm{E}-04$ \\
Standard deviation & $1.12 \mathrm{E}-01$ & $3.13 \mathrm{E}-01$ \\
Max & $1.58 \mathrm{E}+00$ & $2.60 \mathrm{E}+00$ \\
Min & $-1.57 \mathrm{E}+00$ & $-5.70 \mathrm{E}+00$ \\
Range & $3.15 \mathrm{E}+00$ & $8.30 \mathrm{E}+00$ \\
\hline
\end{tabular}

\subsubsection{Large movement on rock slope at 2,300 m}

Following the same methodology and type of data analysis, the same exercise was conducted on another area of the mine where large displacements were occurring. The key displacement and noise statistics plots are shown in Figures 17, 18 and 19. Table 4 shows the improvement on scan-by-scan: average and median in one order of magnitude, and the standard displacement was reduced to a third, falling within the submillimetre accuracy in technical specifications for radars. Table 5 shows some statistics of the overall accumulated displacement estimated with the two algorithms and compared against an ideal polynomial curve of $2^{\text {nd }}$ degree. It can be seen that the standard deviation is reduced from 2.79 to $1.38 \mathrm{~mm}$, with a reduction in the median from $2.1 \mathrm{~mm}$ down to $-0.25 \mathrm{~mm}$, twice the accuracy promoted for radars under controlled laboratory conditions. 


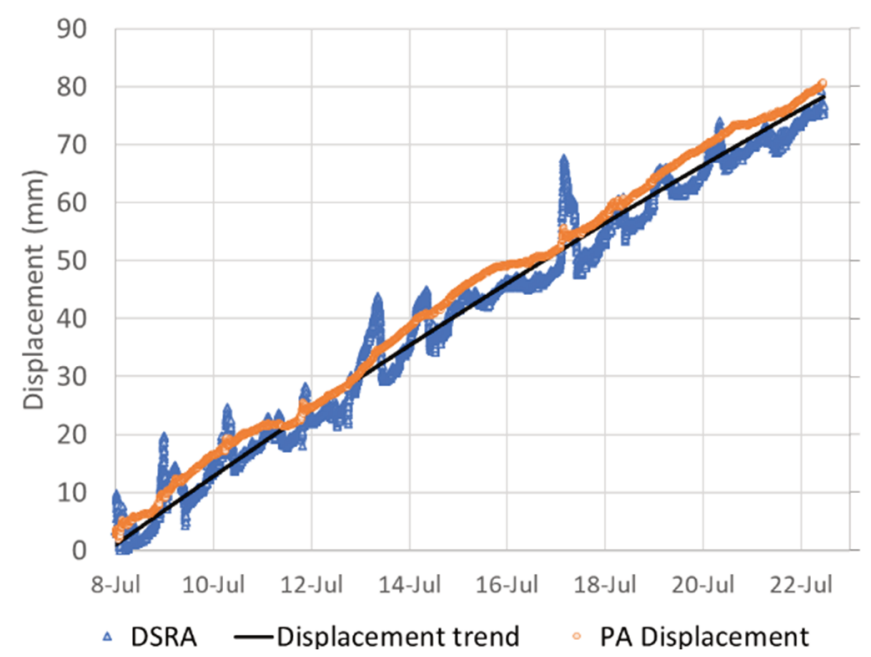

Figure 17 Large movement: dynamic stable reference areas versus precision atmospherics on a large-moving area

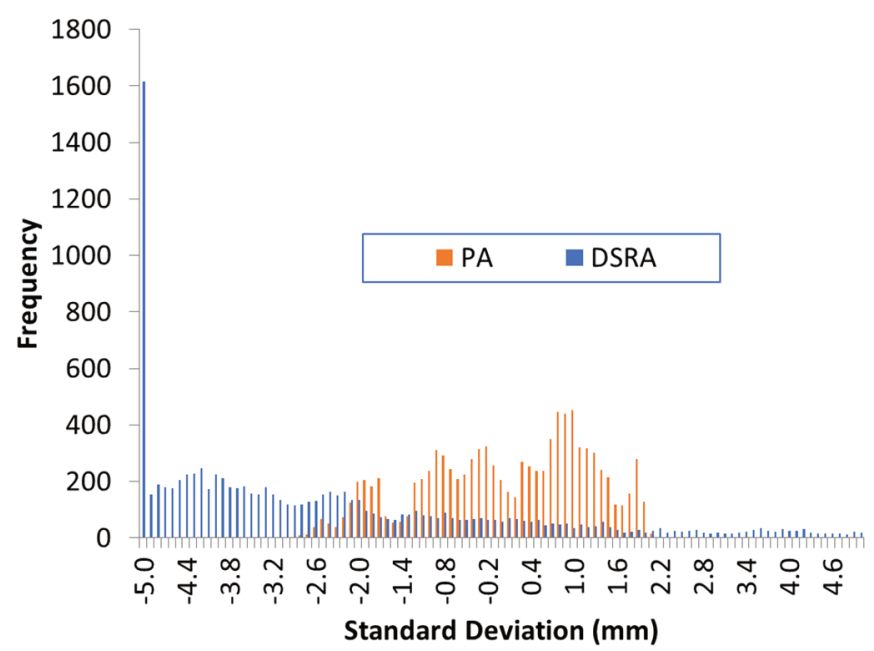

Figure 18 Large movement-histogram of errors on total accumulated displacement using precision atmospherics and dynamic stable reference areas

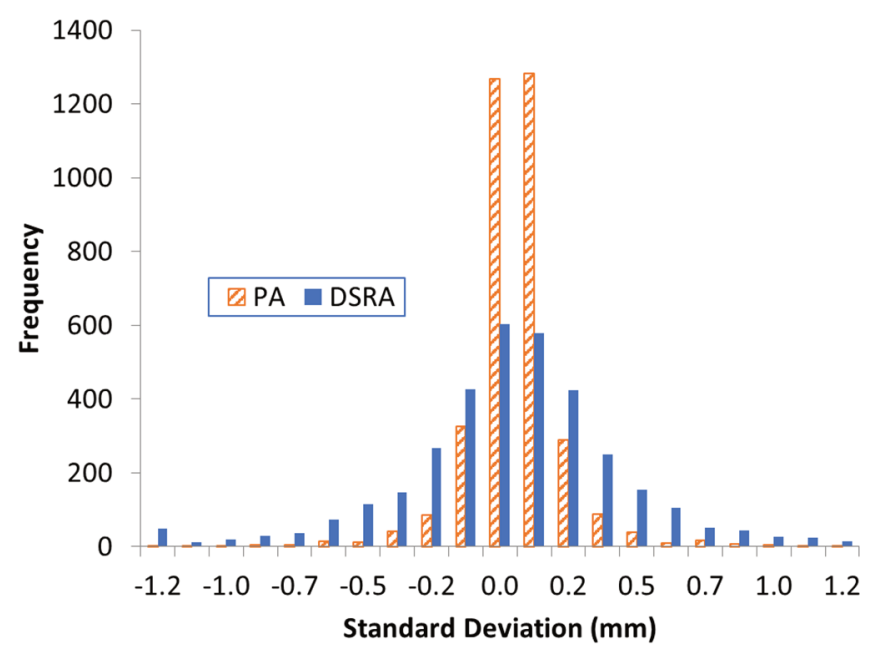

Figure 19 Large movement: histograms of errors on delta displacement (scan-by-scan) using precision atmospherics and dynamic stable reference areas 
Table 4 Large movement statistics: precision atmospherics versus dynamic stable reference areas on large movements on a scan-by-scan basis

\begin{tabular}{lll}
\hline Parameter & Precision atmospherics & Dynamic stable reference areas \\
\hline Average & $8.15 \mathrm{E}-04$ & $1.24 \mathrm{E}-03$ \\
Median & $-9.18 \mathrm{E}-04$ & $-4.12 \mathrm{E}-03$ \\
Standard deviation & $1.79 \mathrm{E}-01$ & $4.49 \mathrm{E}-01$ \\
Max & $2.17 \mathrm{E}+00$ & $3.15 \mathrm{E}+00$ \\
Min & $-1.28 \mathrm{E}+00$ & $-3.27 \mathrm{E}+00$ \\
Range & $3.44 \mathrm{E}+00$ & $6.41 \mathrm{E}+00$ \\
\hline
\end{tabular}

Table 5 Large movement statistics: precision atmospherics versus enhanced deformations on large movements on total accumulated movement

\begin{tabular}{lll}
\hline Parameter & Precision atmospherics & Dynamic stable reference areas \\
\hline Average & $1.88 \mathrm{E}+00$ & $2.36 \mathrm{E}-01$ \\
Median & $2.10 \mathrm{E}+00$ & $-2.52 \mathrm{E}-01$ \\
Standard deviation & $1.39 \mathrm{E}+00$ & $2.80 \mathrm{E}+00$ \\
Max & $4.99 \mathrm{E}+00$ & $1.29 \mathrm{E}+01$ \\
Min & $-2.19 \mathrm{E}+00$ & $-6.64 \mathrm{E}+00$ \\
Range & $7.18 \mathrm{E}+00$ & $1.95 \mathrm{E}+01$ \\
\hline
\end{tabular}

\subsection{Case 3: Super pit}

The PA algorithm was also tested in a very large open pit where several radar manufacturers have failed to deliver good data quality over long periods in broad-area background mode. All the six deformation maps are configured from $-20 \mathrm{~mm}$ to $+20 \mathrm{~mm}$. Notice that the worse examples of DSRA performance were chosen intentionally, in order to highlight the improvements achieved by PA.

Figures 20 and 21 show an area of the mine at 1,400 $\mathrm{m}$ from the radar. The area in white colours of Figure 21 corresponds to an inter-ramp slope. The colour gradient is configured from $-20 \mathrm{~mm}$ to $+20 \mathrm{~mm}$. In Figure 21 , it can be seen as a small deforming area marked by the black circle detected using PA. In Figure 20, the same area is shown with DSRA correction but the saturation in red colour caused by atmospherics prevents the user from discovering the true deformations occurring on the slope. In this case, PA allowed the user to find areas of concern that would not have been detected with the classic DSRA method.

Figure 22 shows a deformation image generated DSRA on another inter-ramp area of the mine. It depicts an area of displacement going away from the radar, which is very strange behaviour for the monitoring configuration applied onsite. After processing the data with PA (Figure 23), a lot of the contamination is removed and the true movement is shown. In this particular case, bad atmospherics acting on the SRAs affected the displacement trend in this area. 


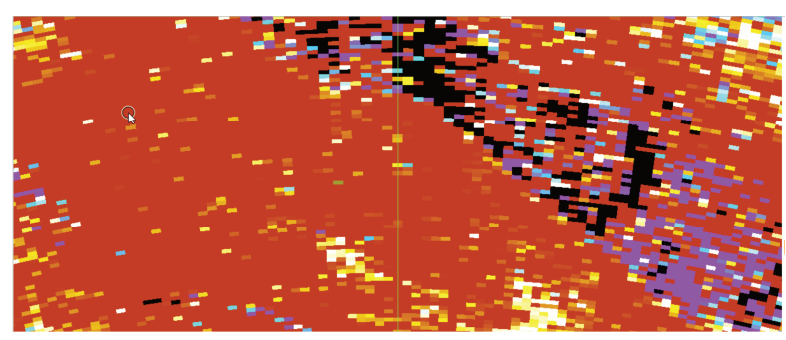

Figure 20 Dynamic stable reference areas displacement image from an area at 1,400 m

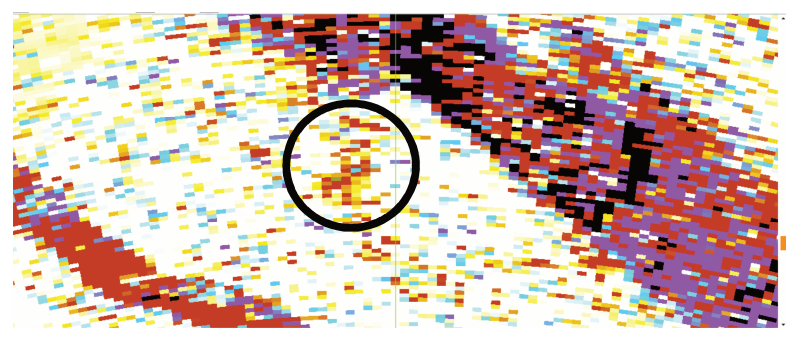

Figure 21 Precision atmospherics displacement image of an area at 1,400 m. A small area of displacement is discovered

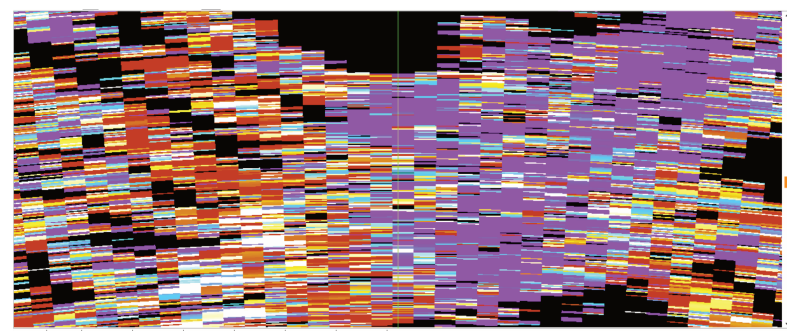

Figure 22 Dynamic stable reference areas displacement image from an area at 2,600 m

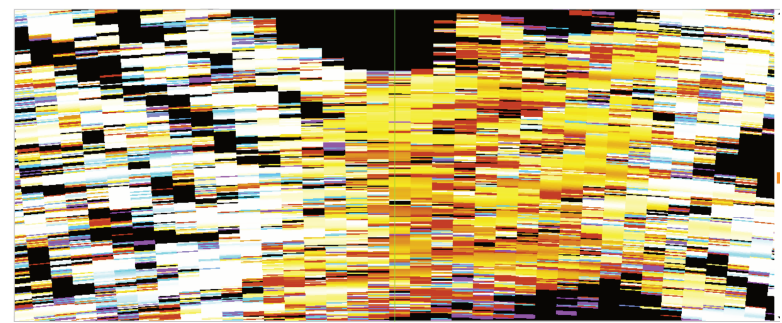

Figure 23 Precision atmospherics displacement image of an area at 2,600 m. Inter-ramp displacement is observed

An area at the longest scan range was chosen: 3,240 m. The displacement maps are shown in Figure 24 and Figure 25 shows the different result obtained by DSRA and PA, respectively. With PA, it is even possible to detect a few pixels with larger displacement than the surrounding areas, caused by the displacement of some loose materials.

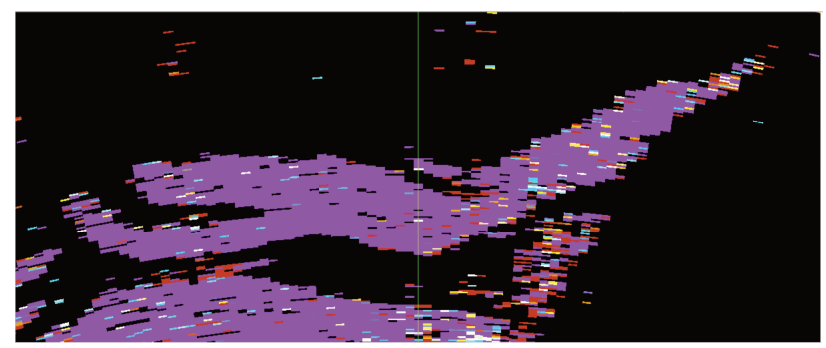

Figure 24 Dynamic stable reference areas displacement image of a far dump 


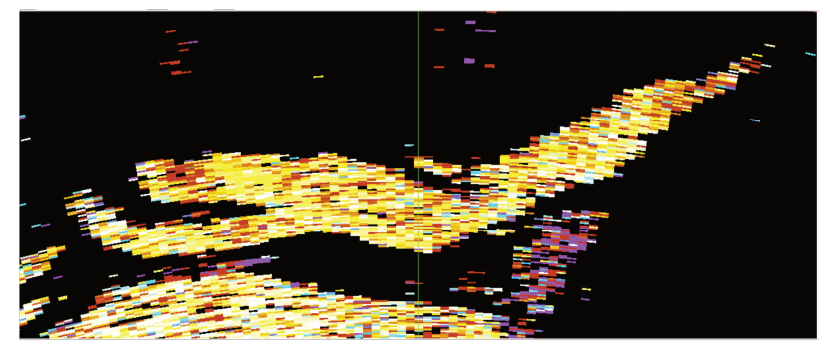

Figure 25 Precision atmospherics displacement image of active dumping with fast and slow displacements

Figure 26 shows the displacement plots of an area located at 3,300 $\mathrm{m}$ on a rock slope with ground response curves on regressive fashion, however, this effect cannot be appreciated at all on the DSRA plots. In fact, it appears to be going away from the radar (negative movement), while the PA clearly shows the movement in the way it really happens which is regressive towards the radar. The same analysis methodology was followed and only the histogram of error is presented in Figure 27. In this figure, it can be seen how the precision displacement once again significantly reduces the level of noise, concentrating most scan-by-scan displacements under the $1 \mathrm{~mm}$ error at long range and with very difficult atmospheric conditions.

These large differences between PA and DSRA trends, occurred under strong atmospherics periods, in which the characteristics of the atmosphere were very different between the SRA and the area of interest. In such a large pit it is normal for the atmosphere to have pockets of air with different density and refractivity. These pockets of different air than the one characterised by the SRA turn the assumption of a homogeneous atmosphere invalid and in consequence, is the use of an incorrect amount of atmospheric correction. When the error is sufficiently large, it can lead to a deformation trend that is different to the correct one, as shown in Figure 26.

Tables 6 and 7 show some of the statistics, in particular a reduction in average and median errors of two orders of magnitude, one in standard deviation for the accumulated displacements, and one order of magnitude in the average scan-by-scan displacement and half the standard deviation.

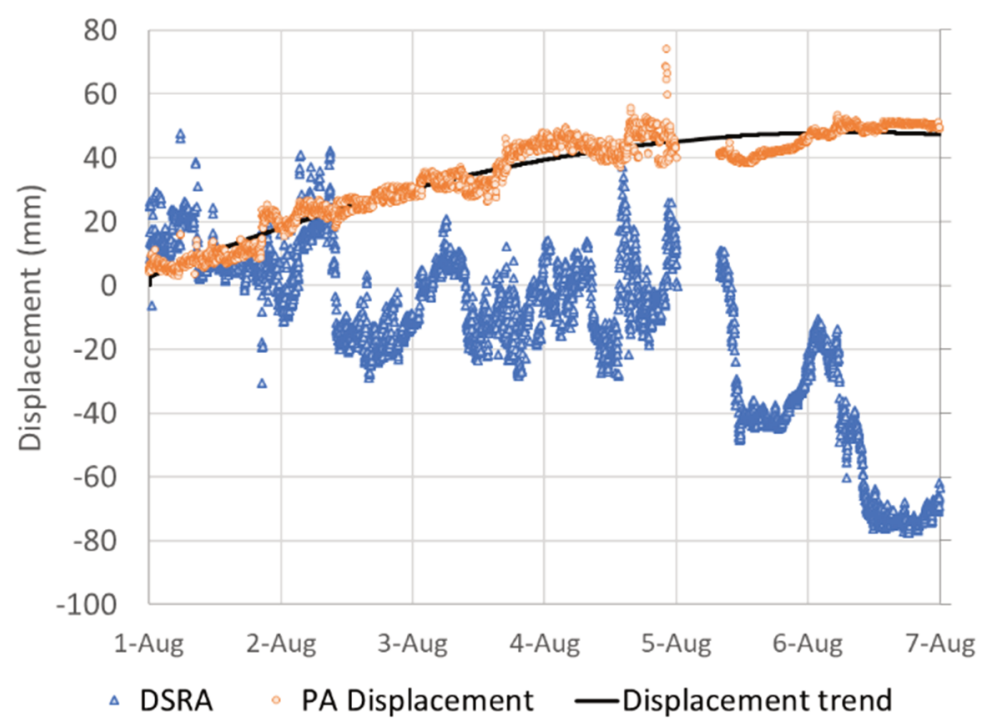

Figure 26 Large open pit, displacement on rock at 3,300 m. Precision atmospherics versus ED 


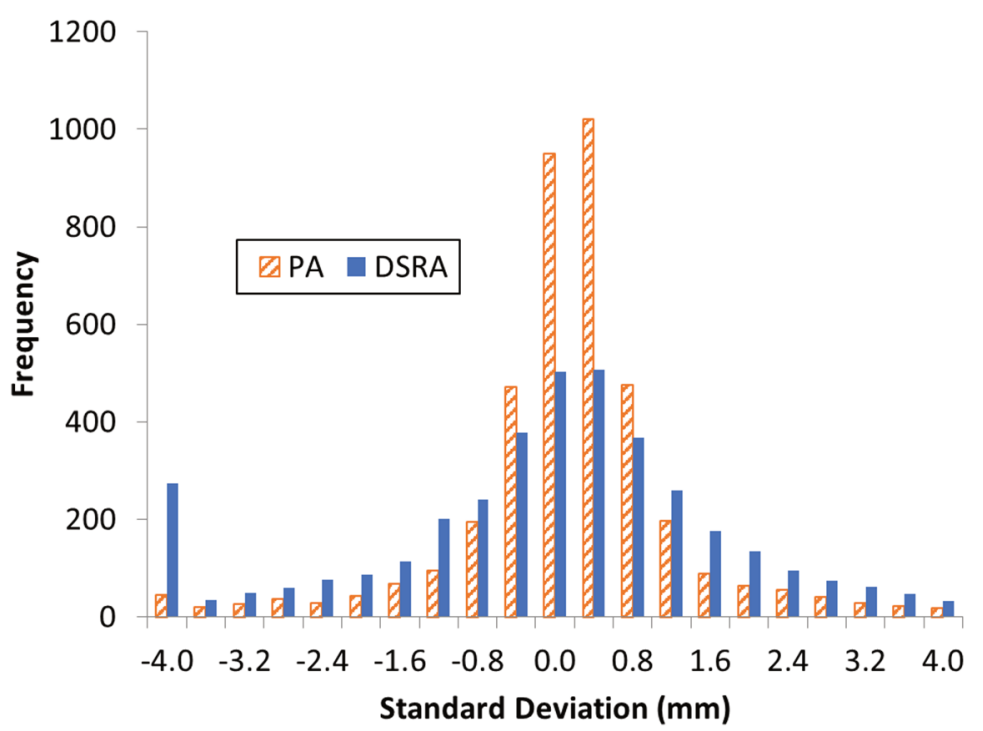

Figure 27 Large open pit: histograms of errors on delta displacement (scan-by-scan) using precision atmospherics and ED

Table 6 Super pit statistics: precision atmospherics versus ED on large movements on a scan-by-scan basis

\begin{tabular}{lll}
\hline Parameter & Precision atmospherics & Dynamic stable reference areas \\
\hline Average & $-1.09 \mathrm{E}-03$ & $-3.16 \mathrm{E}-02$ \\
Median & $1.27 \mathrm{E}-02$ & $1.11 \mathrm{E}-02$ \\
Standard deviation & $1.50 \mathrm{E}+00$ & $3.96 \mathrm{E}+00$ \\
Max & $2.03 \mathrm{E}+01$ & $2.82 \mathrm{E}+01$ \\
Min & $-2.07 \mathrm{E}+01$ & $-3.13 \mathrm{E}+01$ \\
Range & $4.09 \mathrm{E}+01$ & $5.95 \mathrm{E}+01$ \\
\hline
\end{tabular}

Table 7 Super pit statistics: precision atmospherics versus ED on large movements on total accumulated movement

\begin{tabular}{lll}
\hline Parameter & Precision atmospherics & Dynamic stable reference areas \\
\hline Average & $-3.36 \mathrm{E}-01$ & $-3.76 \mathrm{E}+01$ \\
Median & $-3.17 \mathrm{E}-01$ & $-4.03 \mathrm{E}+01$ \\
Standard deviation & $3.89 \mathrm{E}+00$ & $2.84 \mathrm{E}+01$ \\
Max & $2.90 \mathrm{E}+01$ & $4.12 \mathrm{E}+01$ \\
Min & $-9.71 \mathrm{E}+00$ & $-9.70 \mathrm{E}+01$ \\
Range & $3.87 \mathrm{E}+01$ & $1.38 \mathrm{E}+02$ \\
\hline
\end{tabular}

\section{$5 \quad$ Performance during blasting}

Figures 28 and 29 show the result of the atmospheric correction during a blast. These two maps show the significant difference between the two algorithms tested. The improvement in the quality of the deformation maps is very clear, with PA being much more accurate. This same performance was observed on deformation maps over long periods of time. The noise generated in DSRA is caused by a mix between a dust plumb and disturbances in the SRA chosen, which was affected by the blast. 


\section{Implications on alarming}

Figures 30 and 31 show displacement (red), velocity over 180 minutes (blue), and an alarm threshold of $\pm 1 \mathrm{~mm} / \mathrm{h}$ (green), all calculated with DSRA and PA. The alarm used is extremely tight, in particular for a pixel chosen at $1,500 \mathrm{~m}$ distance from the radar and under strong atmospheric conditions. This type of alarm is typically very noisy and time-demanding for geotechnical engineers. The spikes coloured in pink are scans that would have triggered the alarm. Figure 30, using DSRA correction, shows many occurrences of unwanted alarms that do not trigger using PA, as shown in Figure 31, where alarm activations only occur on periods of real acceleration of the rock mass.

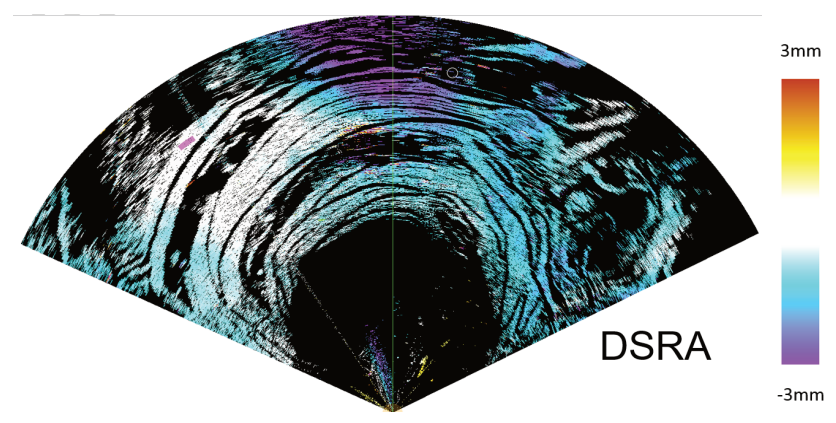

Figure 28 Displacement map after a blast using dynamic stable reference areas

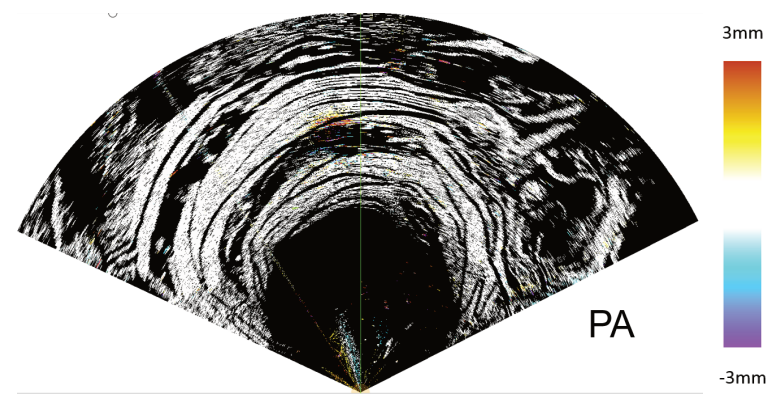

Figure 29 Displacement map after a blast using precision atmospherics
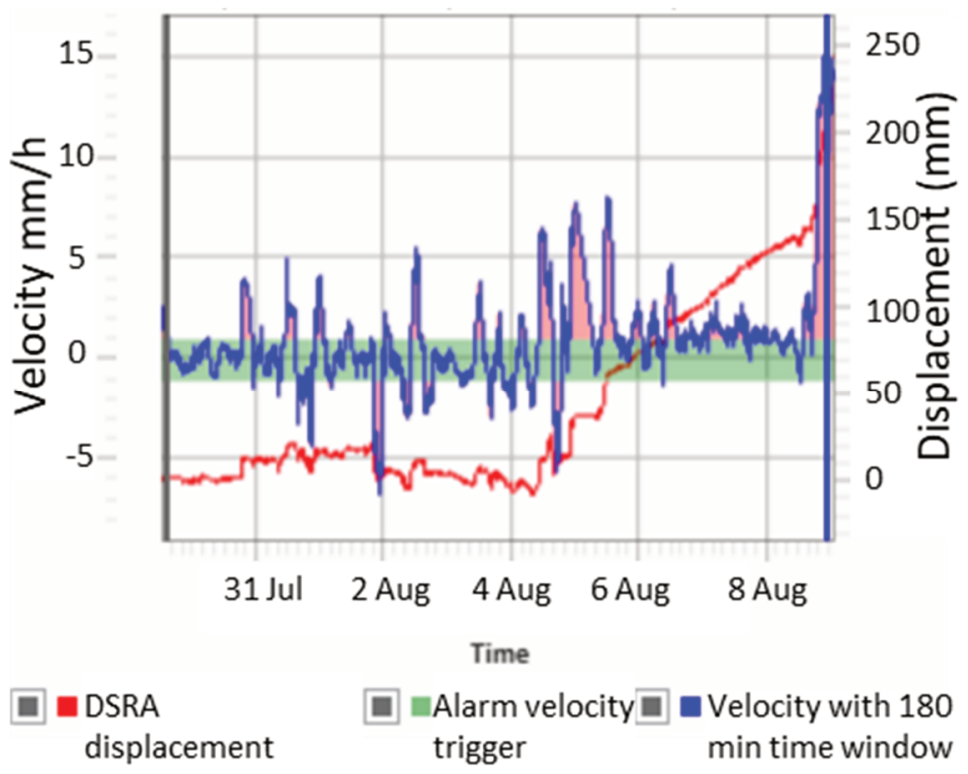

Figure 30 Alarm simulation using dynamic stable reference areas with a velocity calculated over 180 minutes and using $1 \mathrm{~mm} / \mathrm{h}$ as velocity threshold 


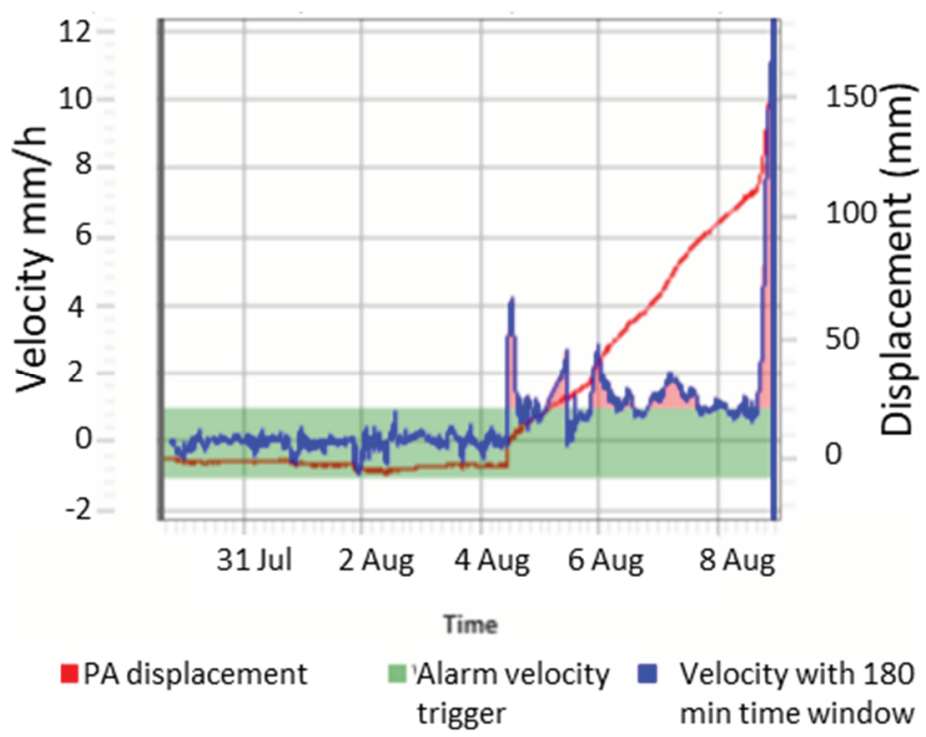

Figure 31 Alarm simulation using precision atmospherics algorithm with a velocity calculated over 180 minutes and using $1 \mathrm{~mm} / \mathrm{h}$ as velocity threshold

With PA, geotechnical engineers will be able to use tighter alarms with less activations due to environmental conditions. This should deliver improvements in safety, productivity, communication, ease of use and quality of life for all of those involved with using radar technology. All of these benefits can take place without any detrimental effect on safety, in comparison with existing atmospheric correction techniques based on SRA.

\section{Conclusion}

Radar technology has evolved continuously since its adaptation to the mining industry in order to meet the demands of growing mine sites. Both RAR and SAR are being used in the mining industry (Bellett et al. 2018). Each radar technology has advantages and disadvantages, as well as the users who have their own preferences. Beyond the radar technology is the software that processes the data they produce, from the signal processing to atmospheric correction and alarming tools. This paper describes the different aspects of the radar technology that have a geotechnical impact, with an emphasis on atmospheric correction as a critical step to obtain high-quality data under adverse atmospheric conditions.

The Precision Atmospherics (PA) algorithm introduced in this paper has shown significant improvements in many different test conditions: in small, medium and large pits; in dry and rainy environments; in periods with snow and plumbs of dust; with layered and highly heterogeneous atmospheres; and at sea level and high altitude. This algorithm has been benchmarked against the SRA technique and has been found as suitable for rapid brittle failures and for long-term large movements, producing data of better quality than the previous algorithms, bringing into the industry another tool for safety-critical monitoring and background applications.

Precision Atmospherics represents a step change in radar technology for open pit mines. It has been developed by teams of geotechnical engineers and radar scientists based on experience around the world. This technique has been developed in order to improve the data quality produced by ground-based radars, based on limitations found when working with mine geotechs around the world.

The noise reduction and improved data quality that Precision Atmospherics brings, described in this paper, it is possible to consider the use of tighter alarms that track the rock mass displacement better and that are less affected by atmospheric disturbances. 


\section{Acknowledgements}

The authors acknowledge the contribution of several colleagues at GroundProbe: David Noon and Lachlan Campbell for their technical and corporate support; John Beevers and Brian Gillespie for funding us in this quest for geotechnical solutions; and Karl Janke and Charl Van Ryhn for writing special software for us to try. We also thank several anonymous mines that allowed GroundProbe to test the radars over months or years during the development of this new algorithm. Without their support, we would have never had the chance to try our solutions in the worst atmospheric conditions of the world.

\section{References}

Bellett, P, Noon, D, Leva, D \& Rivolta, C 2015, '3D and 2D radars for open-pit slope monitoring', in TR Stacey (ed.), Proceedings of the 2015 International Symposium on Slope Stability in Open Pit Mining and Civil Engineering, The Southern African Institute of Mining and Metallurgy, Johannesburg.

Crosetto, M, Michele, Monserrata, O, Cuevas-Gonzáleza, M, Devanthéry, M \& Crippa, B 2016, 'Persistent scatterer interferometry: a review', ISPRS Journal of Photogrammetry and Remote Sensing, vol. 115, pp. 78-89.

Pieraccini, M \& Miccinesi, L 2019, 'Ground-based radar interferometry: a bibliographic review', Remote Sensing, vol. 11, issue 9, https://doi.org/10.3390/rs11091029

Reeves, B, Noon, D, Stickley, G \& Longstaff, D 2001, 'Slope stability radar for monitoring open pit walls. Subsurface and surface sensing technologies and applications III', C Nguyen (ed.), Proceedings of SPIE, vol. 4491, pp. 57-67. 